\title{
Studi Sebaran Material Padatan Tersuspensi di Muara Sungai Sambong, Kabupaten Batang
}

\author{
Ahmad Fikri Delardi ${ }^{1}$, Siddhi Saputro ${ }^{1}$, Warsito Atmodjo ${ }^{1}$, Heriyoso Setyono ${ }^{1}$, Rikha Widiaratih ${ }^{1}$, \\ Aris Ismanto ${ }^{1}$
}

${ }^{1}$ Departemen Oseanografi, Fakultas Perikanan dan Ilmu Kelautan, Universitas Diponegoro

Jl. Prof. Sudarto, SH Tembalang Tlp. / Fax. (024)7474698 Semarang 50275

Email corresponding author: oseanography@live.undip.ac.id

\begin{abstract}
Abstrak
Muara Sungai Sambong berpotensi mengalami pendangkalan akibat pengendapan sedimen tersuspensi. Kali Sambong terus mengalami pendangkalan karena sedimentasi dan sampah sekaligus alur menuju muara pantai yg mengalami penyempitan. Tujuan dari penelitian ini adalah untuk mengetahui sebaran Materi Padatan Tersuspensi (MPT) di Muara Sungai Sambong, Kabupaten Batang, Jawa Tengah. Penelitian dimulai dari tahap pengambilan data di lapangan pada tanggal 7-9 Maret 2017 di Perairan Muara Sungai Sambong, Batang dan tahap pengolahan serta analisis data hasil pengukuran lapangan. Materi yang digunakan meliputi data primer berupa sampel air laut serta data lapangan kecepatan dan arah arus saat pasang maupun surut selama 3 hari, sedangkan data sekunder berupa data pasang surut bulan Maret 2017 dan citra GeoEye tahun 2017. Penelitian ini menggunakan metode analisis kuantitatif model, penentuan lokasi pengambilan sampel air menggunakan metode purposive sampling, pengambilan data arus menggunakan metode lagrange. Model matematik yang digunakan adalah Mike21 Flow Model FM untuk pola arus dan metode interpolasi sebaran MPT dengan ArcGIS menggunakan metode Natural Neighbor. Berdasarkan hasil dari penelitian ini menunjukkan bahwa kecepatan arus pada kondisi pasang menuju surut memiliki nilai antara $0,16 \mathrm{~m} / \mathrm{dt}-1,11$ $\mathrm{m} / \mathrm{dt}$, sedangkan pada kondisi surut menuju pasang memiliki nilai antara $0,16 \mathrm{~m} / \mathrm{dt}-1,25 \mathrm{~m} / \mathrm{dt}$. Nilai material padatan tersuspensi pada kondisi pasang menuju surut memiliki nilai antara 0,08 - 0,29 $\mathrm{g} / \mathrm{L}$, sedangkan pada kondisi surut menuju pasang memiliki nilai antara $0,06-0,35 \mathrm{~g} / \mathrm{L}$. Berdasarkan hasil penelitian dapat disimpulkan bahwa pengaruh arus terhadap sebaran konsentrasi MPT cukup tinggi.
\end{abstract}

Kata Kunci : Materi Padatan Tersuspensi (MPT), Mike21 Flow Model FM, Arus

\begin{abstract}
Sambong estuary potentially suffering to shallow as the result of suspended sedimentation. Sambong river is shallowing due to sedimentation and debris which also narrowing the river channel. The purpose of this study is to observe Total Suspended Solid (TSS) distribution in Sambong Estuary, Batang Regency, Central Java. The study was begin from field collecting data on 7-9 March 2017 in Sambong Estuary waters, Batang and then the data proceed and analized. Material of this study was consist of primary data, which are seawater sampel, current velocity and direction while tide and neap, and secondary data, which are tidal data on March 2017 and GeoEye image on 2017. Quantitative model analysis was used in this study, purposive sampling method was used on collecting the water sampel and lagrange method was used for current data collecting. Mike21 Flow Model FM was used for current model and TSS interpolation method was using ArcGIS by Natural Neighbor method. The result of this study showed that current velocity in tide to neap condition was $0.16 \mathrm{~m} / \mathrm{s}-1.11 \mathrm{~m} / \mathrm{s}$, while in neap to tide condition was $0.16 \mathrm{~m} / \mathrm{s}-1.25 \mathrm{~m} / \mathrm{s}$. Total Suspended Solid value tide to neap condition was $0.08 \mathrm{~g} / \mathrm{L}-0.29 \mathrm{~g} / \mathrm{L}$, while in neap to tide condition was $0.06 \mathrm{~g} / \mathrm{L}-0.35 \mathrm{~g} / \mathrm{L}$. According to this study the effect of current to TSS was high.
\end{abstract}

Keywords : Total Suspended Solid (TSS), Mike21 Flow Model FM, Current 


\section{PENDAHULUAN}

Sungai Sambong merupakan salah satu sungai yang berada di Kabupaten Batang tepatnya di desa Karangasem Utara yang mempunyai pelabuhan Kabupaten Batang. Di sungai Sambong banyak nelayan yang hilir mudik masuk sungai setiap harinya.

Muara sungai merupakan tempat bermuaranya hasil dari aktivitas manusia seperti kegiatan industri. Meningkatnya aktivitas ini akan berdampak pada muara sungai itu sendiri karena hasil dari proses kegiatan industri akan menghasilkan limbah buangan baik padat maupun cair yang mengendap di muara sungai. Muara sungai berfungsi sebagai tempat pengeluaran dan pembuangan debit sungai yang membawa material yang disuplai dari darat terutama material padatan tersuspensi serta limbah hasil aktivitas manusia. Material ini akan teraduk di kolom perairan sebagian akan mengendap di muara sungai dan sisanya akan diteruskan ke laut.

Alaerts dan Santika (1987) menjelaskan, zat padat tersuspensi dapat diklasifikasikan menjadi zat padat terapung yang bersifat organik dan anorganik. Zat padat terendap adalah zat padat dalam suspensi yang dalam keadaan tenang dapat mengendap setelah waktu tertentu karena pengaruh gaya beratnya. Keberadaan material padatan tersuspensi di perairan dapat berupa pasir, lumpur, tanah liat, koloid, serta bahan-bahan organik seperti plankton dan organisme lain.

Analisis arus di Perairan Batang sangat dibutuhkan karena untuk mengetahui pola arusnya. Arus merupakan salah satu faktor hidro-oseanografi yang dapat mempengaruhi dalam proses persebaran material padatan tersuspensi di perairan tersebut. Konsentrasi material padatan tersuspensi ini berpotensi menyebabkan pendangkalan sehingga menyebabkan terhambatnya aliran sungai ke laut dan terganggunya alur pelayaran kapal nelayan yang mengendap di muara sungai dengan tingkat sedimentasinya yang tinggi. Tujuan dari penelitian ini adalah untuk mengetahui sebaran material padatan tersuspensi serta pengaruh arus terhadap sebaran konsentrasi material padatan tersuspensi permukaan di lokasi penelitian.

\section{MATERI DAN METODE}

Materi yang digunakan dalam penelitian ini merupakan data primer dan data sekunder. Data primer berupa sampel air laut serta data lapangan kecepatan dan arah arus saat pasang maupun surut selama 3 hari mulai tanggal 7-9 Maret 2017, di Perairan Sambong, Kabupaten Batang. Data sekunder meliputi data Pasang Surut bulan Maret 2017 dari BMKG (Badan Meteorologi, Klimatologi dan Geofisika) dan Citra Satelit GeoEye Google Earth tahun 2017.

Pengambilan data dilakukan pada 7-9 Maret 2017. Lingkup daerah penelitian terletak pada koordinat $6^{\circ} 52^{\prime} 16^{\prime \prime}$ LS sampai 6 $52^{\prime} 45^{\prime \prime}$ LS dan 109 44'47” BT sampai 10945'13" BT.

Metode penelitian yang digunakan dalam penelitian ini adalah metode analisis kuantitatif model. Menurut Punch (1998), metode penelitian kuantitatif merupakan penelitian empiris dimana data adalah dalam bentuk sesuatu yang dapat dihitung/angka. Penelitian kuantitatif memusatkan pada pengumpulan dan analisis data dalam bentuk numerik dimana pemodelan merupakan gejala di alam yang dapat dimodelkan dalam skala yang kecil dengan menggunakan model matematis atau dengan menggunakan angka.

Pengambilan sampel menggunakan cara purposive sampling method yaitu mengambil sebagian kecil sampel air dari lokasi penelitian tetapi hasilnya mewakili kondisi perairan pada lokasi penelitian (Hadi, 1979). Peta titik pengambilan sampel ditunjukkan pada Gambar 1. 


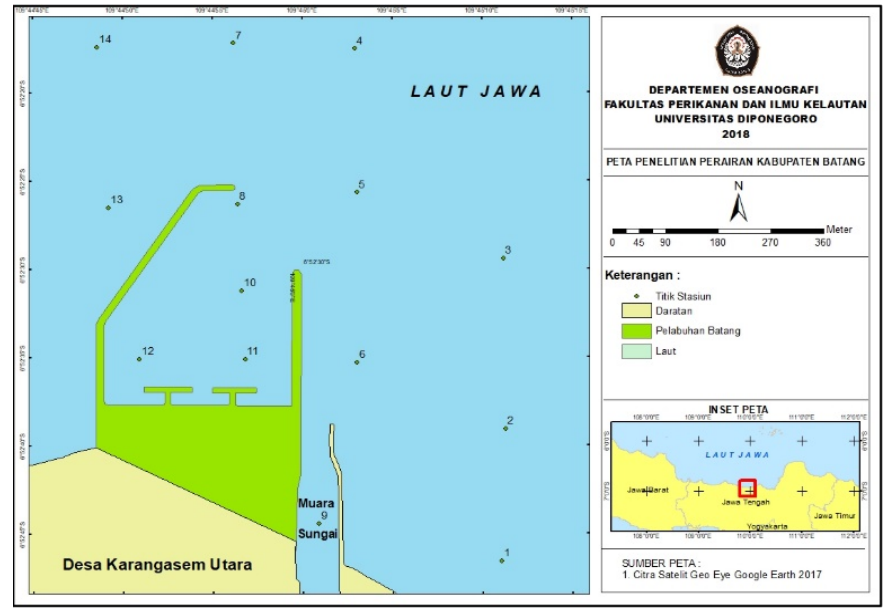

Gambar 1. Peta Titik Pengambilan Sampling

\section{Analisis Data Material Padatan Tersuspensi}

Analisis material padatan tersuspensi dalam penelitian ini menurut Alaerts dan Santika (1987) menggunakan metode gravimetri. Tahapan analisis tersebut adalah sebagai berikut.

1. Kertas saring Whatman berukuran $0.42 \mu \mathrm{m}$ ditimbang menggunakan timbangan digital terlebih dahulu untuk mendapatkan berat awal kertas.

2. Sampel dihomogenkan, kemudian disaring sekitar $100 \mathrm{ml}$ dalam alat penyaringan dan partikelnya akan ditampung oleh kertas saring.

3. Kertas saring dikeringkan menggunakan vacuum oven selama 10 menit dengan suhu $\pm 105^{\circ} \mathrm{C}$.

4. Kertas saring ditimbang kembali untuk medapatkan berat akhir. Hasil selisih berat awal dan akhir merupakan berat sedimen tersuspensi tersebut.

5. Menghitung nilai konsentrasi MPT menururt Alaerts dan Santika (1987) dengan menggunakan rumus

Keterangan:

$$
M P T=\frac{a-b}{c} g / l i t e r
$$

$\mathrm{a}=$ massa kertas saring dan MPT yang berada di kertas saring $(\mathrm{g})$

$\mathrm{b}=$ massa kertas saring $(\mathrm{g})$

$\mathrm{c}=$ volume sampel air (liter)

Setelah diperoleh nilai konsentrasi MPT seluruh stasiun, kemudian dilakukan interpolasi untuk mengetahui sebaran MPT secara horizontal pada kedalaman permukaan. Metode interpolasi yang dilakukan adalah dengan interpolasi geostatistik Natural Neighbor. Metode ini dikenal juga sebagai interpolasi Sibson atau "Area Stealing" (Sibson, 1981). Sifat dasar metode interpolasi ini adalah lokal, dimana hanya menggunakan sampel yang berada disekitar titik yang ingin diinterpolasi, dan hasil yang diperoleh akan mirip dengan ketinggian titik sampel yang digunakan sebagai nilai masukan proses interpolasi.

\section{Analisis Data Arus}

Pengukuran data Arus di lapangan dengan menggunakan metode Lagrange, yaitu metode pengukuran arus dengan mengikuti jejak suatu alat (biasanya pelampung) (Sudarto, et all., 2013). Metode ini secara konvensional dilakukan dengan cara terjun langsung ke lapangan untuk mendapatkan data jarak, lokasi, dan waktu pengukuran. Tahapan pengukuran tersebut adalah sebagai berikut:

- alat-alat pengukuran seperti: bola duga; stopwatch; dan kompas.

- bola duga diturunkan ke air laut hingga baling-baling seluruhnya tercelup dan tidak muncul di permukaan.

- pergerakan jarak, waktu, dan arah dari bola duga diukur dengan menggunakan kompas tembak untuk arah dan stopwatch untuk catatan waktunya. 
- kecepatan arus dihitung dengan menggunakan rumus sebagai berikut :

$$
V=\frac{s}{t}
$$

Keterangan:

$\mathrm{V}=$ Kecepatan Arus (m/s)

$\mathrm{s}=\operatorname{Jarak}(\mathrm{m})$

$\mathrm{t}=$ waktu (s)

\section{Verifikasi Model}

Perhitungan validasi digunakan untuk menguji kebenaran hasil model. Perhitungan validasi dilakukan dengan menghitung nilai Cost Function (CF). CF merupakan nilai non-dimensional yang menghitung perbedaan antara nilai-nilai model dengan data pengukuran lapangan menunjukkan kecocokan antara dua kumpulan data. Kriteria kelayakan hasil model untuk rumus Cost Function adalah sangat baik untuk nilai $\mathrm{CF}<1$, baik untuk nilai CF $1-2$, lumayan untuk nilai CF $2-3$ dan buruk untuk nilai $\mathrm{CF}>3$. Perhitungan $\mathrm{CF}$ menggunakan rumus sebagai berikut:

$$
C F=\frac{1}{N} \sum_{n=1}^{N} \frac{\left|D_{n}-M_{n}\right|}{\sigma_{D}}
$$

Keterangan:

(George et, al., 2010)

$\mathrm{N} \quad$ : jumlah data pengamatan

$\mathrm{n} \quad$ : nilai ke $\mathrm{n}$, dengan $\mathrm{n}=1,2,3, \ldots$

D : nilai pengamatan

$\mathrm{M} \quad$ : nilai model

$\sigma_{D} \quad$ : standar deviasi

\section{Analisis Korelasi Data}

Hubungan antara data Arus dan persebaran nilai Konsentrasi MPT, didapatkan dengan teknik korelasi. Metode yang digunakan untuk menentukan koefisien korelasi menggunakan persamaan Pearson correlation (Sudjana, 1992).

$$
r=\frac{\sum x y-\frac{\left(\sum x\right)\left(\sum y\right)}{n}}{\sqrt{\left(\sum x^{2}-\frac{\left(\sum x\right)^{2}}{n}\right)\left(\sum y^{2}-\frac{\left(\sum y\right)^{2}}{n}\right)}}
$$

Keterangan:

$$
\begin{array}{ll}
\mathrm{r} & \text { : Pearson correlation coefficient } \\
\mathrm{x} & \text { : Variabel } \mathrm{x} \\
\mathrm{y} & \text { : Variabel } \mathrm{y} \\
\mathrm{n} & \text { : Jumlah sampel }
\end{array}
$$

Untuk menginterpretasi kekuatan hubungan antara dua variabel terbagi kedalam beberapa kriteria berdasarkan nilai koefisien korelasinya. Seperti ditunjukkan pada Tabel 1.

Tabel 1. Nilai kekuatan hubungan hasil koefisien korelasi (Pearson correlation)

\begin{tabular}{ll}
\hline Koefisisen Korelasi & Interpretasi Hubungan \\
\hline $0-0.2$ & Sangat Rendah \\
$0.2-0.4$ & Rendah \\
$0.4-0.7$ & Cukup Tinggi \\
$0.7-1.0$ & Tinggi \\
\hline
\end{tabular}




\section{HASIL DAN PEMBAHASAN \\ Arus lapangan}

Berdasarkan hasil pengukuran lapangan diperoleh kecepatan dan arah arus setiap stasiun serta waktu saat pengambilan sampel, untuk kondisi surut menuju pasang ditunjukkan dalam Tabel 2, dan untuk kondisi pasang menuju surut ditunjukkan dalam Tabel 3 .

Tabel 2. Kecepatan dan arah arus lapangan saat kondisi surut menuju pasang

\begin{tabular}{|c|c|c|c|c|c|c|}
\hline \multirow{3}{*}{ Stasiun } & \multirow{2}{*}{\multicolumn{2}{|c|}{ Titik Koordinat }} & \multicolumn{2}{|c|}{ Menuju Pasang } & \multirow{2}{*}{\multicolumn{2}{|c|}{$\begin{array}{l}\text { Waktu Pengambilan } \\
\text { Sampel }\end{array}$}} \\
\hline & & & $\mathbf{v}$ & $\alpha$ & & \\
\hline & $\mathbf{L S}$ & BT & $(\mathrm{m} / \mathrm{dt})$ & $\left(\mathbf{N} . .{ }^{0} E\right)$ & Tanggal & Jam \\
\hline 9 & $-6,879,003$ & $109,750,287$ & 1,25 & 85,2 & 07-Mar-17 & 14.00 \\
\hline 6 & $-6,876,475$ & $109,750,882$ & 0,164 & 200,4 & 07-Mar-17 & 14.10 \\
\hline 1 & $-6,879,598$ & $109,753,113$ & 0,610 & 300,5 & 07-Mar-17 & 14.30 \\
\hline 2 & $-6,877,516$ & $109,753,172$ & 0,351 & 315,6 & 07-Mar-17 & 14.41 \\
\hline 3 & $-6,874,839$ & $109,753,142$ & 0,370 & 340,6 & 07-Mar-17 & 15.05 \\
\hline 4 & $-6,871,538$ & $109,750,852$ & 0,267 & 330,6 & 07-Mar-17 & 15.29 \\
\hline 7 & $-6,871,448$ & $109,748,978$ & 0,385 & 340,6 & 07-Mar-17 & 15.42 \\
\hline 14 & $-6,871,508$ & $109,746,866$ & 0,263 & 330,6 & 07-Mar-17 & 15.52 \\
\hline 13 & $-6,874,036$ & $109,747,045$ & 0,467 & 0,1 & 07-Mar-17 & 16.02 \\
\hline 12 & $-6,876,416$ & $109,747,521$ & 0,509 & 330,6 & 07-Mar-17 & 16.19 \\
\hline 11 & $-6,876,416$ & $109,749,157$ & 0,347 & 340,6 & 07-Mar-17 & 16.26 \\
\hline 10 & $-6,875,345$ & $109,749,097$ & 0,573 & 340,6 & 07-Mar-17 & 16.32 \\
\hline 8 & $-6,873,977$ & $109,749,038$ & 0,615 & 0,0 & 07-Mar-17 & 16.41 \\
\hline 5 & $-6,873,798$ & $109,750,882$ & 0,393 & 90,2 & 07-Mar-17 & 16.53 \\
\hline
\end{tabular}

Tabel 3. Kecepatan dan arah arus lapangan saat kondisi pasang menuju surut

\begin{tabular}{|c|c|c|c|c|c|c|}
\hline \multirow{3}{*}{ Stasiun } & \multirow{2}{*}{\multicolumn{2}{|c|}{ Titik Koordinat }} & \multicolumn{2}{|c|}{ Menuju Surut } & \multirow{2}{*}{$\begin{array}{l}\text { Waktu } \\
\text { Sampel }\end{array}$} & Pengambilan \\
\hline & & & $\mathbf{v}$ & $\alpha$ & & \\
\hline & LS & BT & $(\mathrm{m} / \mathrm{dt})$ & $\begin{array}{l}(\mathbf{N} . . \\
\left.{ }^{\mathbf{0}} \mathbf{E}\right)\end{array}$ & Tanggal & Jam \\
\hline 14 & $-6,871,508$ & $109,746,866$ & 0,370 & 70,1 & 08-Mar-17 & 08.47 \\
\hline 13 & $-6,874,036$ & $109,747,045$ & 0,556 & 40,7 & 08-Mar-17 & 08.54 \\
\hline 12 & $-6,876,416$ & $109,747,521$ & 0,526 & 60,1 & 08-Mar-17 & 09.08 \\
\hline 11 & $-6,876,416$ & $109,749,157$ & 0,274 & 30,6 & 08-Mar-17 & 09.12 \\
\hline 10 & $-6,875,345$ & $109,749,097$ & 0,645 & 65,1 & 08-Mar-17 & 09.17 \\
\hline 8 & $-6,873,977$ & $109,749,038$ & 0,503 & 110,2 & 08-Mar-17 & 09.24 \\
\hline 5 & $-6,873,798$ & $109,750,882$ & 0,168 & 325,6 & 08-Mar-17 & 09.34 \\
\hline 9 & $-6,879,003$ & $109,750,287$ & 1,111 & 340,6 & 09-Mar-17 & 09.00 \\
\hline 6 & $-6,876,475$ & $109,750,882$ & 0,241 & 90,2 & 09-Mar-17 & 09.08 \\
\hline 1 & $-6,879,598$ & $109,753,113$ & 0,171 & 30,6 & 09-Mar-17 & 09.26 \\
\hline 2 & $-6,877,516$ & $109,753,172$ & 0,299 & 30,6 & 09-Mar-17 & 09.34 \\
\hline 3 & $-6,874,839$ & $109,753,142$ & 0,222 & 20,4 & 09-Mar-17 & 09.56 \\
\hline 4 & $-6,871,538$ & $109,750,852$ & 0,417 & 120,2 & 09-Mar-17 & 10.20 \\
\hline 7 & $-6,871,448$ & $109,748,978$ & 0,392 & 75,1 & 09-Mar-17 & 10.30 \\
\hline
\end{tabular}


Saat kondisi pasang menuju surut, arus di lapangan menunjukkan bahwa terjadi arus yang dominan ke arah laut atau menjauhi garis pantai. Kecepatan arus tertinggi terjadi pada daerah muara sungai yaitu stasiun 9 dengan nilai $1,11 \mathrm{~m} / \mathrm{dt}$. Hal ini diakibatkan karena adanya debit dari dalam sungai. Fenomena ini diperkuat oleh pernyataan Triatmodjo (1999) bahwa kondisi ketika air surut, volume air mengalir keluar dalam periode waktu tertentu yang tergantung pada tipe pasang surut, sehingga kecepatan arus selama air surut tersebut besar dan cukup potensial untuk membentuk muara sungai. Kecepatan arus terendah terjadi pada stasiun 5 yaitu dengan kecepatan arus $0,16 \mathrm{~m} / \mathrm{dt}$.

\section{Pola arus model}

Pola pemodelan arus saat kondisi pasang menuju surut menunjukkan vektor arah arus dominan menuju Utara menjauhi garis pantai. Pola pemodelan arus ini dapat dilihat pada Gambar 4. Sedangkan, pola pemodelan arus saat kondisi surut menuju pasang menunjukkan vektor arah arus dominan juga menuju Tenggara mendekati garis pantai, pola pada kondisi ini dapat dilihat pada Gambar 5.

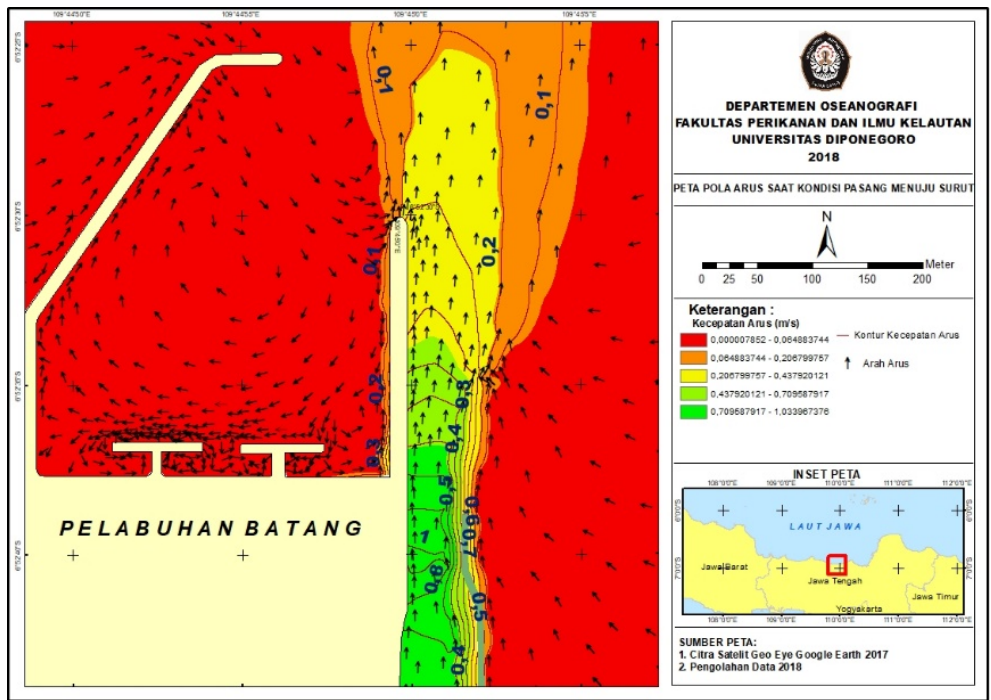

Gambar 4. Peta Pola Arus saat Kondisi Pasang menuju Surut

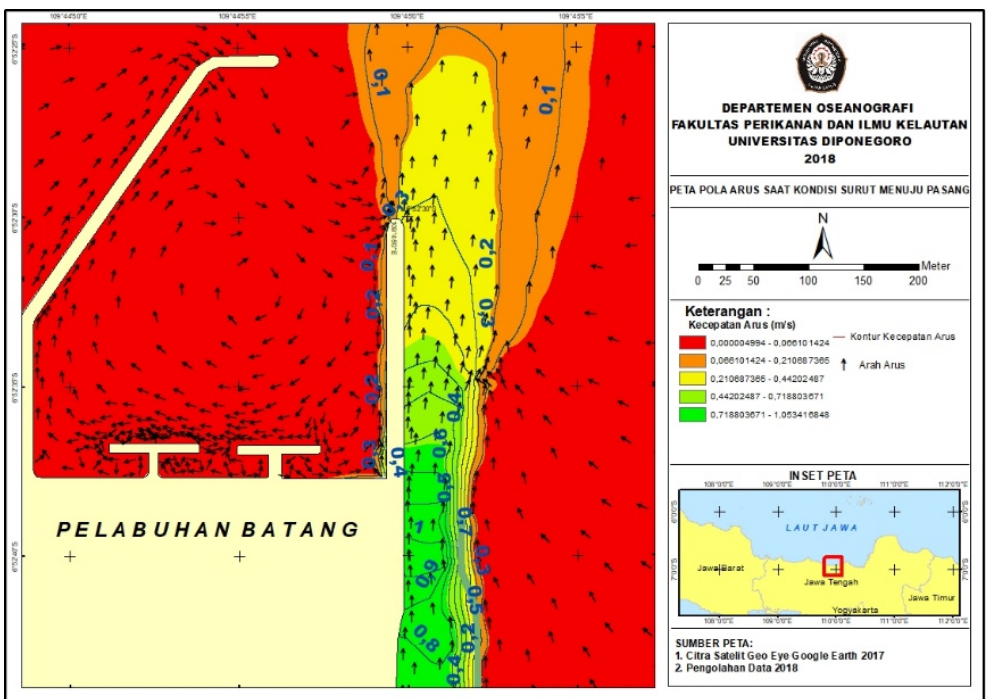

Gambar 5. Peta Pola Arus saat Kondisi Surut menuju Pasang 


\section{Verifikasi arus lapangan dan model}

Verifikasi arus lapangan dan arus model dalam penelitian ini menggunakan analisis statistika Cost Function (CF). Nilai CF diperoleh dari perbandingan antara data arus pengamatan dengan arus model pada permukaan perairan selama waktu pengukuran. Data yang diverifikasi adalah data komponen u dan v. Hasil verifikasi pada model didapatkan nilai CF komponen u sebesar 0,099; dan untuk komponen v sebesar 0,079. Nilai-nilai ini masih sangat diterima karena termasuk dalam kriteria "sangat baik". Grafik perbandingan data arus lapangan dan arus model ditunjukkan pada Gambar 6-7.

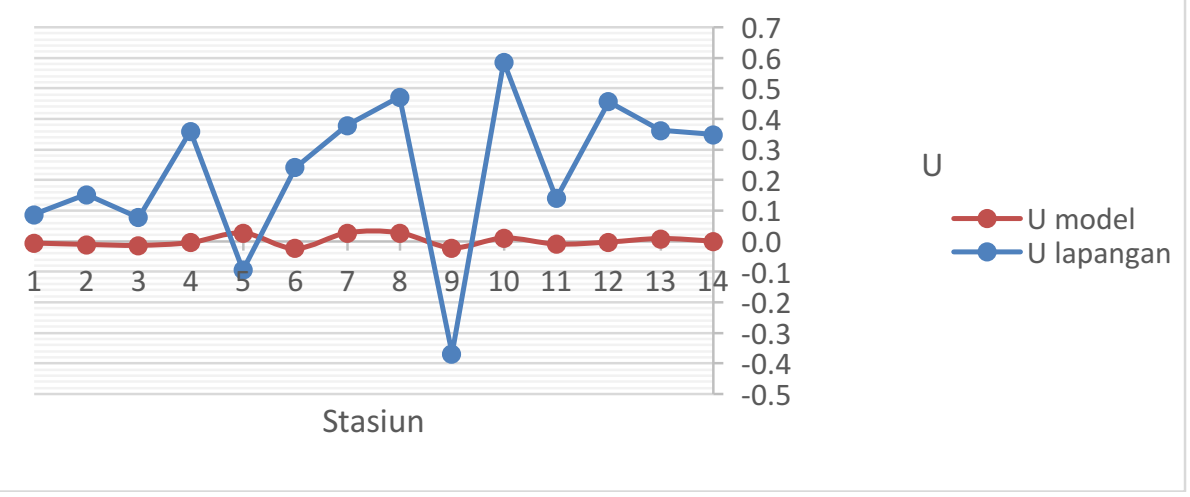

Gambar 6. Grafik Perbandingan Arus Lapangan dan Arus Model pada Arus komponen U

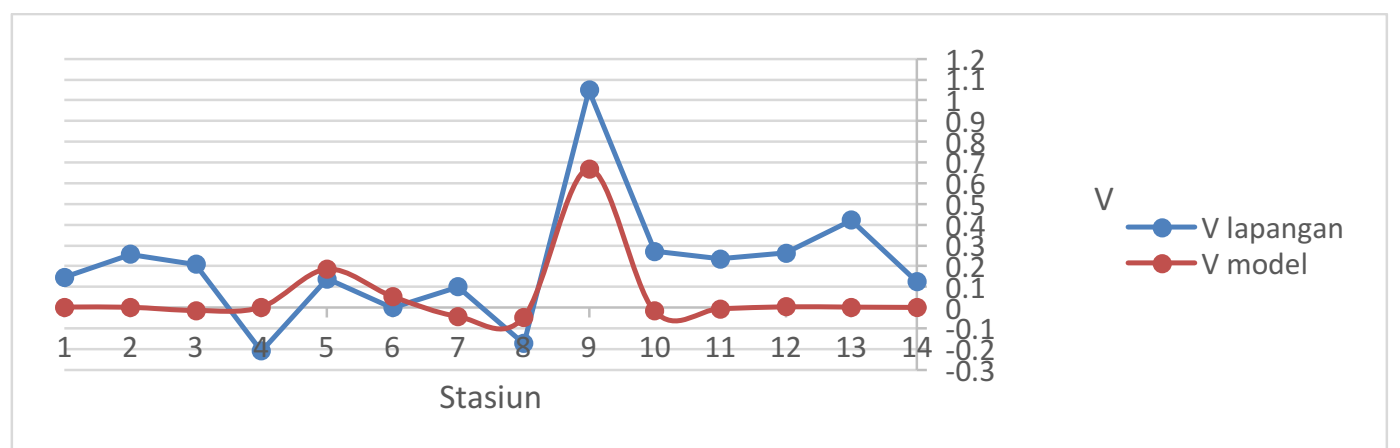

Gambar 7. Grafik Perbandingan Arus Lapangan dan Arus Model pada Arus komponen V

\section{Material padatan tersuspensi}

Berdasarkan analisis data lapangan, konsentrasi material padatan tersuspensi diperoleh nilai maksimal $0,29 \mathrm{~g} / \mathrm{L}$, minimal $0,08 \mathrm{~g} / \mathrm{L}$ dan rata-rata $0,16 \mathrm{~g} / \mathrm{L}$ pada kondisi pasang menuju surut. Sedangkan pada kondisi surut menuju pasang nilai maksimal $0,35 \mathrm{~g} / \mathrm{L}$, minimal $0,06 \mathrm{~g} / \mathrm{L}$ dan rata-rata $0,199 \mathrm{~g} / \mathrm{L}$

\section{Pola arus dan sebaran material padatan tersuspensi}

Berdasarkan hasil pengolahan serta analisis data model arus dan sebaran konsentrasi material padatan tersuspensi pada kedua kondisi ditunjukkan pada Tabel 4-5. Peta sebaran MPT pada kedua kondisi akan ditunjukkan pada Gambar 8-9. 
Tabel 4. Konsentrasi Material Padatan Tersuspensi pada Kondisi Pasang Menuju Surut

\begin{tabular}{cccc}
\hline \multirow{2}{*}{ Stasiun } & MPT & $\mathrm{v}$ & Arah \\
\cline { 2 - 4 } & $(\mathrm{g} / \mathrm{L})$ & $(\mathrm{m} / \mathrm{dt})$ & $\left({ }^{\circ}\right)$ \\
\hline 1 & 0,11 & 0,171 & 30,6 \\
2 & 0,09 & 0,299 & 30,6 \\
3 & 0,08 & 0,222 & 20,4 \\
4 & 0,25 & 0,417 & 120,2 \\
5 & 0,08 & 0,168 & 325,6 \\
6 & 0,13 & 0,241 & 90,2 \\
7 & 0,25 & 0,392 & 75,1 \\
8 & 0,11 & 0,503 & 110,2 \\
9 & 0,29 & 1,111 & 340,6 \\
10 & 0,19 & 0,645 & 65,1 \\
11 & 0,16 & 0,274 & 30,6 \\
12 & 0,19 & 0,526 & 60,1 \\
13 & 0,13 & 0,556 & 40,7 \\
14 & 0,2 & 0,370 & 70,1 \\
\hline
\end{tabular}

Tabel 5. Konsentrasi Material Padatan Tersuspensi pada Kondisi Surut Menuju Pasang

\begin{tabular}{cccc}
\hline \multirow{2}{*}{ Stasiun } & MPT & $\mathrm{v}$ & Arah \\
\cline { 2 - 4 } & $(\mathrm{g} / \mathrm{L})$ & $(\mathrm{m} / \mathrm{dt})$ & $\left({ }^{\circ}\right)$ \\
\hline 1 & 0,13 & 0,610 & 300,5 \\
2 & 0,06 & 0,351 & 315,6 \\
3 & 0,13 & 0,370 & 340,6 \\
4 & 0,21 & 0,267 & 330,6 \\
5 & 0,09 & 0,393 & 90,2 \\
6 & 0,17 & 0,164 & 200,4 \\
7 & 0,26 & 0,385 & 340,6 \\
8 & 0,2 & 0,615 & 0,0 \\
9 & 0,35 & 1,25 & 85,2 \\
10 & 0,25 & 0,573 & 340,6 \\
11 & 0,29 & 0,347 & 340,6 \\
12 & 0,28 & 0,509 & 330,6 \\
13 & 0,19 & 0,467 & 0,1 \\
14 & 0,18 & 0,263 & 330,6 \\
\hline
\end{tabular}

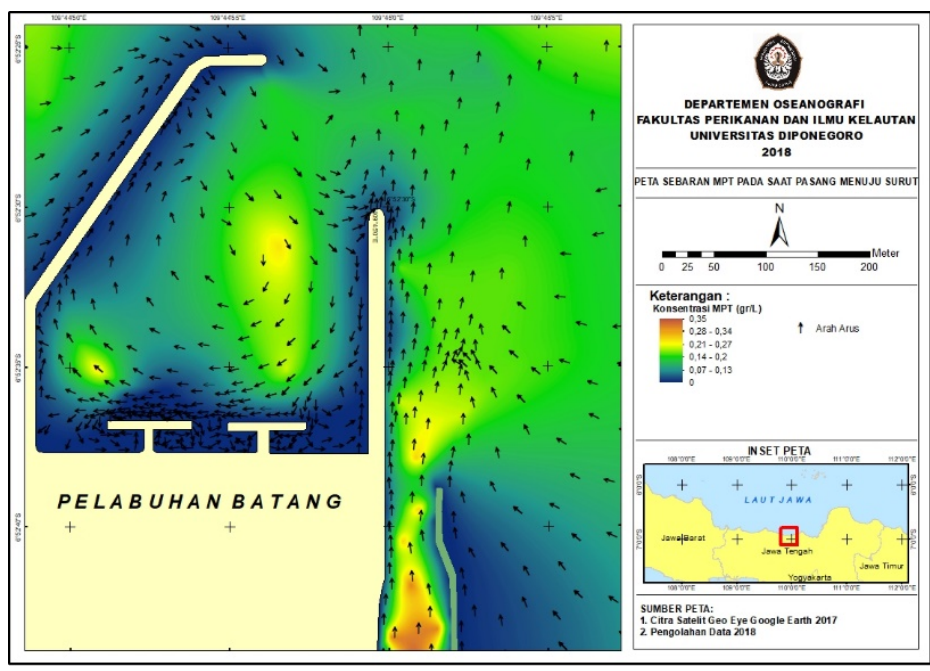

Gambar 8. Peta Sebaran MPT pada saat Pasang menuju Surut di Muara Sungai Sambong 


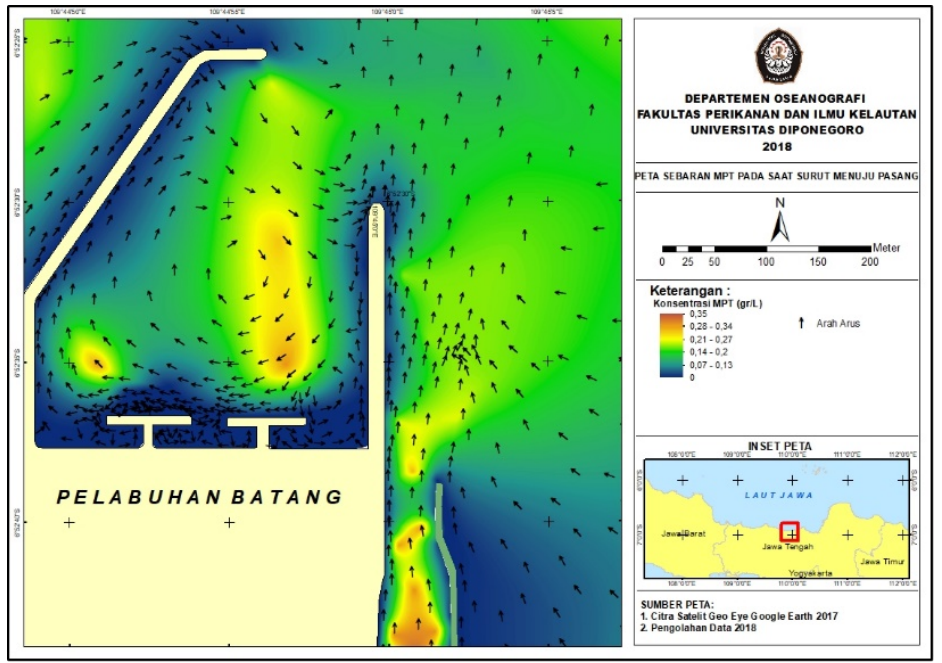

Gambar 9. Peta Sebaran MPT pada saat Surut menuju Pasang di Muara Sungai Sambong

Pada kondisi pasang menuju surut, nilai konsentrasi MPT tertinggi terjadi pada stasiun 9 yang dimana memang terletak di sekitar muara sungai Sambong, yaitu sebesar 0,29 g/L. Setelahnya, yang tertinggi juga terjadi pada stasiun 4 dan 7 yang terletak searah dengan arah arus menuju ke laut, dan juga masih searah dari muara aungai, yaitu sebesar $0,25 \mathrm{~g} / \mathrm{L}$. Hal ini didukung pendapat Triatmodjo (1999), bahwa muara sungai berfungsi sebagai pengeluaran air dari darat, sehingga menyebabkan stasiun yang terdekat dari darat memiliki konsentrasi tertinggi. Nilai konsentrasi MPT terendah terjadi pada stasiun 3 dan 5 dengan konsentrasi $0,08 \mathrm{~g} / \mathrm{L}$.

Pada kondisi surut menuju pasang, konsentrasi tertinggi masih tetap pada stasiun 9 dengan nilai konsentrasinya yaitu $0,35 \mathrm{~g} / \mathrm{L}$. Nilai tertinggi berikutnya adalah pada lokasi stasiun yang berada di dalam kolam pelabuhan (stasiun 11) dengan nilai kosentrasinya $0,29 \mathrm{~g} / \mathrm{L}$. Hal ini mungkin disebabkan karena sedimen yang terbawa oleh arus saat pasang ini, terjebak di dalam kolam pelabuhan karena adanya arah arus yg memutar di dalam kolam pelabuhan (bisa dilihat pada Gambar. 9), sehingga menyebabkan nilai konsentrasi yang cukup tinggi. Pada stasiun 12, yang letaknya sangat dekat dengan stasiun 11 atau masih berada di dalam kolam pelabuhan, nilai konsentrasinya pun cukup tinggi juga, yaitu sebesar $0,28 \mathrm{~g} / \mathrm{L}$.

\section{Analisis korelasi pengaruh arus terhadap sebaran MPT}

Untuk mengetahui hubungan antara data arus dan sebaran nilai konsentrasi MPT, maka bisa didapatkan dengan teknik korelasi. Metode yang digunakan untuk menentukan koefisien korelasi kali ini adalah menggunakan persamaan Pearson correlation (Sudjana, 1992). Maka hasil yang didapatkan untuk nilai koefisien korelasinya pada kedua kondisi ditunjukkan oleh Gambar 10-11.

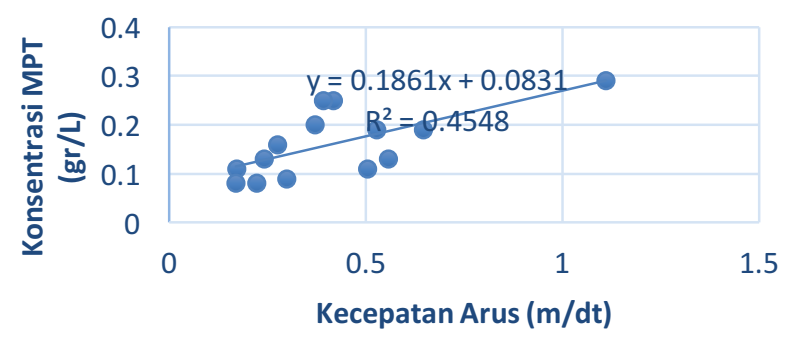

Gambar 10. Grafik Koefisien Korelasi Pengaruh Arus Terhadap Sebaran MPT Saat Kondisi Pasang Menuju Surut 


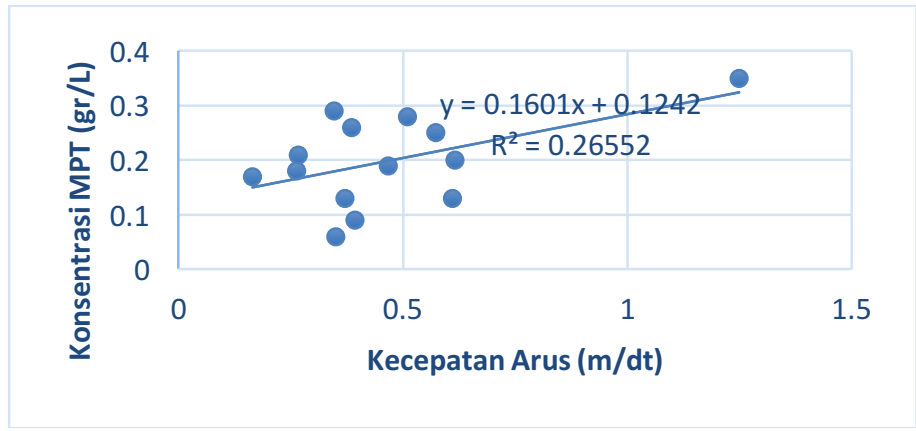

\section{Gambar 11. Grafik Koefisien Korelasi Pengaruh Arus Terhadap Sebaran MPT Saat} Kondisi Surut Menuju Pasang

Pada kondisi surut, grafik yang ditunjukkan pada Gambar 10 yang didapatkan nilai $\mathrm{R}^{2}$ sebesar 0,4548. Dengan begitu, setelah di akar kuadratkan maka kita akan mendapatkan Nilai $R=0,6744$. Menurut Sudjana (1992), untuk nilai koefisien korelasi Pearson atau dalam hal ini R, dalam rentang 0,4-0,7, masuk ke dalam indikator interpretasi hubungan yang cukup tinggi. Berarti dalam hal ini dengan nilai $\mathrm{R}$ tersebut, maka pengaruh arus dalam persebaran MPT di muara sungai Sambong, pada saat kondisi pasang menuju surut, pengaruhnya cukup tinggi, sesuai dengan hasil perhitungan nilai koefisien korelasinya.

Pada saat kondisi pasang, kita bisa lihat grafik yang ditunjukkan pada Gambar 11. bahwa disana didapatkan nilai $\mathrm{R}^{2}$ sebesar 0,2655 . Dengan begitu, setelah di akar kuadratkan maka kita akan mendapatkan Nilai $R=0,5153$. Berarti dalam hal ini dengan nilai $R$ tersebut, maka pengaruh arus dalam persebaran MPT di muara sungai Sambong, pada saat kondisi surut menuju pasang pengaruhnya cukup tinggi, sesuai dengan hasil perhitungan nilai koefisien korelasinya.

\section{KESIMPULAN}

Arus yang berperan pada perairan muara sungai Sambong adalah arus pasang surut. Kecepatan arus tertinggi yaitu pada muara sungai dengan kecepatan $1,25 \mathrm{~m} / \mathrm{dt}$ (terjadi pada kondisi surut menuju pasang). Kecepatan arus terendah terjadi pada stasiun 6, yaitu dengan kecepatan arus $0,164 \mathrm{~m} / \mathrm{dt}$. Nilai konsentrasi material padatan tersuspensi pada kondisi pasang menuju surut memiliki nilai rata-rata $0,161 \mathrm{~g} / \mathrm{L}$. Sedangkan, nilai konsentrasi material padatan tersuspensi pada kondisi surut menuju pasang memiliki nilai rata-rata $0,199 \mathrm{~g} / \mathrm{L}$. Pada kondisi pasang menuju surut, nilai koefisien korelasinya sebesar 0,6744 , sedangkan pada saat kondisi surut menuju pasang memiliki nilai koefisien korelasi sebesar 0,5153. Dengan kedua nilai koefisien korelasi tersebut, dapat disimpulkan bahwa pengaruh arus terhadap sebaran MPT di permukaan pada muara sungai Sambong cukup tinggi.

\section{DAFTAR PUSTAKA}

Alaerts, G dan S.S Santika. 1987. Metode Penelitian Alir. Usaha Nasional, Surabaya.

George, M. S., Bertino, L., Johannessen O. M., Samuelsen A. 2010. Validation of a Hybrid Coordinate Model for The Indian Ocean. Journal of Operational Oceanography. 3(2) : $25-38$. Nensen Environmental and Remote Sensing Center. Bergen. Norway.

Hadi, S. dan I.M. Radjawane. 2009. Arus Laut. Institut Teknologi Bandung, Bandung.

Punch, M. 1998. Introduction to Social Research: Quantitative and Qualitative Approaches. Sage. London. 51 Hal.

Sibson, R., 1981, “A Brief Descripiton of Natural Neighbor Interpolation”. Chapter 2 in Interpolating Multivariate Data. New York: John Wiley \& Sons, pp. 21-36.

Sudarto, W. Patty dan A. A. Tarumingkeng. 2013. Kondisi Arus Permukaan Di Perairan Pantai: Pengamatan Dengan Metode Lagrangian. Jurnal Ilmu dan Teknologi Perikanan Tangkap. 1 (3) : 98-102.

Triatmodjo, B. 1999. Teknik Pantai. Beta Offset, Yogyakarta. 